\title{
Tanah, Otoritas Politik, dan Stabilitas Ekonomi Kerajaan Mataram Islam
}

\section{Zaid Munawar}

munawarzaid@yahoo.com

Universitas Nahdlatul Ulama Surakarta

\begin{abstract}
This article aims to examine the issue of land, political authority, and economic stability of the Islamic Mataram Kingdom in the era of Sultan Agung. This study uses the historical method by carrying out steps such as topic selection, heuristics, verification, interpretation and historiography. The results showed that Sultan Agung as a king had full authority over land management throughout the territory of the Islamic Mataram Kingdom. In order for the land to be managed properly, several policies were implemented, namely appointing land management officials at the central and regional levels, dividing the land in Kutagara, Negara Agung, Mancanegara and Pasisiran into three types, such as narawita land, perdikan land and lungguh land, determining the area land to nobles and royal officials, and prioritized land management for agriculture. This policy succeeded in increasing the welfare of the palace, nobles, royal officials, and farmers as well as strengthening the influence of the Islamic Mataram Kingdom on other areas in trading activities and regional expansion.
\end{abstract}

Keywords: Land, Political Authority, Economic Stability, Islamic Mataram Kingdom

\begin{abstract}
Abstrak
Artikel ini bertujuan mengkaji tentang persoalan tanah, otoritas politik, dan stabilitas ekonomi Kerajaan Mataram Islam era Sultan Agung. Studi ini menggunakan metode sejarah dengan melakukan langkah-langkah seperti pemilihan topik, heuristik, verifikasi, interpretasi dan historiografi. Hasil penelitian menunjukkan bahwa Sultan Agung sebagai seorang raja memiliki otoritas penuh terhadap pengelolaan tanah di seluruh wilayah kekuasaan Kerajaan Mataram Islam. Agar tanah tersebut dapat dikelola dengan baik, maka diterapkan beberapa kebijakan, yaitu menunjuk pejabat pengelola tanah di pusat dan daerah, membagi tanah di Kutagara, Negara Agung, Mancanegara dan Pasisiran menjadi tiga jenis, seperti tanah narawita, tanah perdikan dan tanah lungguh, menetapkan luas tanah lungguh kepada para bangsawan dan pejabat kerajaan, dan memprioritaskan pengelolaan tanah untuk pertanian. Kebijakan tersebut berhasil meningkatkan kesejahteraan istana, bangsawan, pejabat kerajaan, dan para petani serta menguatkan pengaruh Kerajaan Mataram Islam terhadap wilayah lain dalam kegiatan perdagangan dan ekspansi wilayah.
\end{abstract}

Kata Kunci: Tanah, Otoritas Politik, Stabilitas Ekonomi, Kerajaan Mataram Islam

\section{Pendahuluan}


Sultan Agung adalah putra mahkota dari Panembahan Krapyak dan Ratu Mas Adi Dyah Banowati yang lahir tahun 1593 (Moedjanto, 1986; Susilo, 2020). Penyebutan tahun ini didasarkan karena ketika Panembahan Krapyak meninggal pada tahun 1613 M, Sultan Agung sudah menginjak usia 20 tahun. Di usia ini Sultan Agung naik tahta menjadi raja di Kerajaan Mataram Islam. Ia memiliki keinginan lebih besar daripada Panembahan Senopati dan Ki Gede Pemanahan sebagai peletak dasar terbentuknya Kerajaan Mataram Islam, yaitu ingin menyatukan seluruh wilayah Jawa di bawah kuasanya. Pada masanya, terjadi pemindahan pusat pemerintahan kerajaan dari Kota Gede ke Kerta. Ketika itu situasi politik dalam pemerintahan tidak luput dari ketegangan antara pusat dengan daerah yang ingin melepaskan diri dari kekuasaan Mataram Islam, misalnya, kabupaten yang berada di wilayah Jawa bagian tengah (Burdah, 2017; Kartodirdjo, 1995; Santosa, 2008).

Selain potensi disintegrasi di Jawa bagian tengah, Sultan Agung juga mendapat tantangan besar dari wilayah Jawa bagian timur maupun barat. Di wilayah timur, terdapat Surabaya yang sudah terlebih dahulu menjadi kabupaten yang kuat, baik politik maupun ekonominya. Di samping sebagai Negara kaya karena perdagangannya, Surabaya juga memiliki daerah kekuasaan di sekelilingnya. Kemudian di wilayah barat, Mataram memiliki saingan yang besar pula, yaitu Banten dan VOC di Batavia. Perseteruan Mataram Islam dengan Banten sudah dimulai sejak berdirinya kedua kerajaan ini. Sedangkan VOC merupakan kekuatan baru di Jawa yang mulai merajalela di seluruh Indonesia sejak berhasil merebut Jayakarta dan mendirikan Batavia pada tahun 1619 (Burdah, 2017; Moedjanto, 1987).

Setelah ibukota pindah ke Kerta, Sultan Agung segera mempersiapkan ekspedisi militer guna mewujudkan misinya dalam menyatukan seluruh wilayah Jawa. Strategi yang diterapkan yaitu membentuk sistem keprajuritan yang lebih terorganisir baik di pusat maupun daerah. Di tingkat pusat dibentuk prajurit bernama wiraraja yang terbagi menjadi dua, yaitu pasukan singasari sebagai pengawal kaputren dan pasukan wirasinga sebagai pasukan tempur yang bertugas melawan musuh. Untuk membantu pasukan wirasinga dibentuklah prajurit wiratani di tingkat daerah, yaitu pasukan dari kalangan penduduk desa yang kesehariannya bekerja sebagai petani, namun di kala genting juga dikerahkan sebagai prajurit perang. Pasukan ini tersebar di pelbagai desa dan kecamatan yang diorganisir oleh para wakil raja sebagai komandan perang dengan jumlah prajurit yang berbeda-beda, yaitu panewu (memimpin 1000 prajurit), panatus (memimpin 100 prajurit), panaket (memimpin 50 prajurit), panalawe (memimpin 25 prajurit), paningang-jung (memimpin 10 prajurit), dan panakikil (memimpin 4 prajurit). Kedisiplinan dan semangat tempur yang dimiliki para prajurit tersebut telah menjadi senjata paling perkasa bagi Sultan Agung untuk mewujudkan cita-citanya (Hartoyo, 1996; Sabdacarakatama, 2010).

Dengan kekuatan militer yang dimiliki, Sultan Agung melancarkan misi ekspansi ke wilayah timur sebagai basis kekuatan Surabaya. Secara berturut-turut, penaklukkan berhasil dilakukan terhadap wilayah Lumajang, Lenong, dan Malang (1614), Wirasaba (1615), Lasem (1616), Pasuruan (1617), dan Tuban (1619) (Darmawijaya, 2010). Penaklukkan terhadap Surabaya dilakukan secara periodik dari 
tahun 1620 sampai 1626 dengan taktik mengepung Surabaya dan membinasakan hasilhasil panennya, membendung sungai Brantas sehingga memutus aliran air ke kota, dan menaklukkan Sukadana (1622) dan Madura (1624) sebagai mitranya sehingga memutus sumber suplai ke kota. Dengan taktik ini, maka kekuatan Surabaya berangsur melemah. Akhirnya, pada serangan keenam tahun 1626, Surabaya dapat ditaklukkan sehingga kota-kota dagang di pantai utara sampai ujung timur Jawa berhasil dikuasai oleh Kerajaan Mataram Islam (Moedjanto, 1987; Ricklefs, 2008).

Sejak ditundukkannya Surabaya, Sultan Agung semakin kuat menancapkan hegemoninya atas wilayah Jawa bagian timur. Akan tetapi, melalui perjuangan militer, Sultan Agung masih berupaya mengusir VOC dari bumi Nusantara. Karena keberadaan VOC ternyata bukan hanya untuk berdagang rempah-rempah saja, tetapi semakin hendak menjajah Nusantara ( Pranata, 1977). Hal ini terlihat jelas ketika VOC merebut Jayakarta dari kekuasaan Kesultanan Islam Banten. Di atas reruntuhan Jayakarta, VOC membangun Batavia sebagai pusat kekuasaan militer dan politik yang kemudian semakin merajalela di seluruh Nusantara (Moedjanto, 1986). Akibat hubungan pasang surut antara VOC dan Mataram, meletuslah perang besar pada tahun 1628 dan 1629 di Batavia. Dalam peperangan tersebut, Kerajaan Mataram Islam mengalami kekalahan dan VOC tetap kuat di bawah benteng Batavia.

Sejarah mencatat, era Sultan Agung, Kerajaan Mataram Islam telah mampu menguasai seluruh wilayah Jawa bagian tengah dan timur serta sebagian Jawa bagian barat. Untuk wilayah timur, Giri dan Blambangan termasuk wilayah yang baru bisa ditaklukkan pada masa akhir pemerintahan. Giri ditaklukkan pada tahun 1636, sedangkan Blambangan pada tahun 1640 (Kartodirdjo, 1995). Adapun wilayah Jawa bagian barat yang dikuasai yaitu Cirebon, Ukur, Galuh, Sumedang, Karawang dan lain sebagainya. Dua wilayah yang tidak bisa ditundukkan yaitu Batavia dan Banten. Adapun wilayah luar pulau Jawa yang dapat dikuasai yaitu Madura, Palembang, Banjarmasin, Sukadana dan Makasar (de Graaf, 1989; Febri, 2016).

Dengan serangkaian keberhasilan ekspansi di atas, tentu tanah kekuasaan Kerajaan Mataram Islam menjadi bertambah luas yang terbagi menjadi empat bagian, yaitu Kutagara, Negara Agung, Mancanegara dan Pasisiran (Munawar, 2020). Dalam tradisi jawa, Sultan Agung sebagai raja memiliki kekuasaan yang absolut di seluruh wilayah kekuasaan tersebut. Ia diakui rakyat sebagai pemilik segala sesuatu yang berada dalam naungannya, baik berkaitan dengan harta, benda, bahkan kehidupan manusia di seluruh tanah kekuasaannya (Moedjanto, 1987). Dengan otoritas politik yang dimiliki, ia harus mampu mengelola seluruh tanah kekuasaan yang berhasil ditaklukkan. Sebab pada masanya, selain memiliki arti penting secara politik, tanah juga memiliki arti penting secara ekonomi. Secara politik, penguasaan atas tanah yang luas menjadi bukti bagi kebesaran Kerajaan Mataram Islam di mata negara lain. Secara ekonomi, meningkatnya aktivitas militer menyebabkan bertambahnya kebutuhan kerajaan untuk membiayai militer dalam rangka penaklukkan untuk memperluas wilayah kekuasaan. Keberhasilan pengelolaan tanah di seluruh wilayah kekuasaan ketika itu sangat berpengaruh besar terhadap keberhasilan misi ekspansi selanjutnya. Selain dapat mendukung misi politik kerajaan, keuntungan ekonomi yang didapat dari 
pengelolaan tanah tersebut juga dapat digunakan untuk mendukung kesejahteraan istana dan seluruh penduduk di Kerajaan Mataram Islam.

Secara geografis, wilayah Kutagara dan Negara Agung sebagai pusat kerajaan Mataram Islam terletak di daerah pedalaman Jawa bagian tengah yang bercorak agraris dengan lahan yang sangat luas sebagai ladang penghidupan. Berdasarkan laporan Van Goens, duta dari Belanda, terdapat hamparan sawah yang luas dan indah ketika melewati pintu gerbang Selimbi di sekitar Gunung Merbabu sebagai pintu masuk negeri Mataram. Di sana terdapat banyak desa padat penduduk dengan masing-masing desa terdiri dari 100 atau 150 kepala keluarga atau bahkan mencapai 1000 sampai 1500 kepala keluarga. Kondisi alam di dalamnya sangat subur dan didukung dengan air yang melimpah. Begitu pula di wilayah Mancanegara maupun Pasisiran, terdapat lahan yang begitu luas dan subur (Lombard, 1996; Munawar, 2020). Kondisi alam tersebut sangat menguntungkan secara ekonomi apabila dikelola dengan baik. Menurut Jhon Meynard Keynes, jika sektor pertanian ditetapkan sebagai program utama pembangunan, maka kegiatan ekonomi dalam rangka produksi dan distribusi produk pertanian akan meningkat (Haq, 1996).

Berdasarkan uraian di atas, dapat dilihat bahwa persoalan pengelolaan tanah menjadi satu aspek pemerintahan yang perlu mendapat perhatian Sultan Agung di Kerajaan Mataram Islam. Penguasaan atas tanah yang begitu luas dan kondisi alam yang subur haruslah diimbangi dengan pengelolaan yang baik untuk mendukung berjalannya proses pemerintahan. Tulisan ini ingin mengkaji tentang bagaimana Sultan Agung sebagai seorang pemimpin menggunakan otoritasnya dalam memaksimalkan pengelolaan tanah di wilayah Kerajaan Mataram Islam terutama Kutagara, Negara Agung, Mancanegara dan Pasisiran. Keberhasilan pengelolaan tanah ini akan sangat berpengaruh terhadap stabilitas ekonomi di Kerajaan Mataram Islam.

\section{Metode}

Penelitian ini merupakan penelitian kualitatif yang dilakukan dengan memakai metode sejarah. Di dalam metode ini terdapat lima langkah yang harus dilakukan untuk mencapai tujuan penelitian, yaitu pemilihan topik, heuristik, verifikasi, interpretasi, dan historiografi (Laksono, 2018; Wasino \& Endah Sri, 2018).

Pertama, pemilihan topik. Pada langkah ini peneliti membaca berbagai literatur yang membahas tentang Kerajaan Mataram Islam terutama pada periode Sultan Agung. Dari pembacaan tersebut peneliti menemukan beragam topik kajian tentang Kerajaan Mataram Islam pada masa Sultan Agung yang dilihat dari aspek agama, sosial, budaya, ekonomi, politik, dan pendidikan. Di antara kajian tersebut, aspek politik menjadi bagian yang paling banyak diperhatikan oleh para peneliti terutama ketika melihat kejayaan Kerajaan Mataram Islam dalam memperluas wilayah kekuasaan. Dari aspek ini peneliti tertarik untuk menelaah lebih jauh tentang topik ekonomi dan politik terutama pada persoalan mengenai bagaimana Sultan Agung menggunakan kekuasaannya dalam mengelola tanah di seluruh wilayah kekuasaan untuk menjaga stabilitas ekonomi Kerajaan Mataram Islam. 
Kedua, heuristik. Pada langkah ini peneliti mencari, membaca dan mengumpulkan berbagai literatur dari buku dan jurnal terkait pengelolaan tanah yang dilakukan oleh Sultan Agung di Kerajaan Mataram Islam. Ketiga, setelah mendapatkan sumber-sumber terkait penelitian, peneliti melakukan verifikasi untuk mengkritik atau menilai sumber-sumber tersebut melalui kritik intern dan kritik ekstern. Kritik intern dilakukan dengan menilai secara jelas keakuratan sumber dari mulai isi, bahasa, situasi, gaya maupun ide sumber yang didapat. Adapun kritik ekstern dilakukan untuk menilai keaslian sumber dari mulai bentuk sumber, tanggal pembuatan dan identitas dari pembuat sumber agar teruji validitas dan kredibilitasnya sehingga layak dijadikan sebagai bahan penelitian.

Setelah melalui tahap verifikasi, peneliti melakukan langkah keempat yaitu interpretasi. Pada langkah ini peneliti menafsirkan berbagai data penelitian yang didapat dari sumber-sumber penelitian. Peneliti melakukan sintesis data sejarah tersebut mengenai otoritas Sultan Agung dalam pengelolaan tanah di Kerajaan Mataram Islam untuk menjaga stabilitas ekonomi kerajaan dengan didukung teoriteori penelitian yang relevan. Hasil penafsiran terhadap data-data penelitian tersebut kemudian disusun menjadi sebuah fakta penelitian lalu dihubungan secara logis. Berikutnya dilakukan langkah terakhir, yaitu historiografi. Pada langkah ini peneliti menuliskan hasil penelitian secara sistematis dan kronologi sehingga menjadi sebuah tulisan sejarah yang baik.

\section{Hasil dan Pembahasan}

Konsep politik yang dikembangkan oleh Sultan Agung di Kerajaan Mataram Islam merujuk pada tradisi Jawa yang dikenal dengan doktrin keagungbinataraan (Moedjanto, 1986). Dalam konsep politik ini besarnya kekuasaan raja diistilahkan dengan gung binathara; bau dhendha nyakrawati; wenang wisesa ing sanagari; wicaksana; berbudi bawa leksana, ambeg adil para marta; anjaga tata titi tentreming praja karta tuwin raharja, yang berarti bahwa raja itu: memiliki kekuasaan sebesar kekuasaan dewa; pemelihara hukum dan penguasa dunia; berwenang tertinggi di seluruh negeri; bijaksana; memiliki sikap mulia dan sifat adil terhadap sesama; menjaga keteratutan dan ketentraman hidup rakyat supaya terwujud situasi aman dan sejahtera (Budi Wirianto, 2001; Moedjanto, 1986).

Merujuk pada konsep politik di atas, kekuasaan yang dimiliki oleh Sultan Agung sebagai raja merupakan ketunggalan, utuh dan bulat, tidak tersaingi, tidak terkotak-kotak/terbagi, dan menyeluruh di segala bidang kehidupan (Moedjanto, 1986). Ia adalah pemegang otoritas tertinggi pemerintahan yang memiliki kuasa penuh atas seluruh wilayah dan segala isi yang ada di dalamnya. Melalui kekuasaan tersebut ia mengembangkan sistem pemerintahan yang bersifat sentralistik namun dengan birokrasi yang masih bersifat tradisional, yaitu birokrasi yang merupakan pengembangan rumah tangga raja yang diatur berdasarkan sistem perwilayahan yang terpusat di keraton dan berkembang ke luar sebagaimana tergambar dalam lingkaran konsentris berikut: 


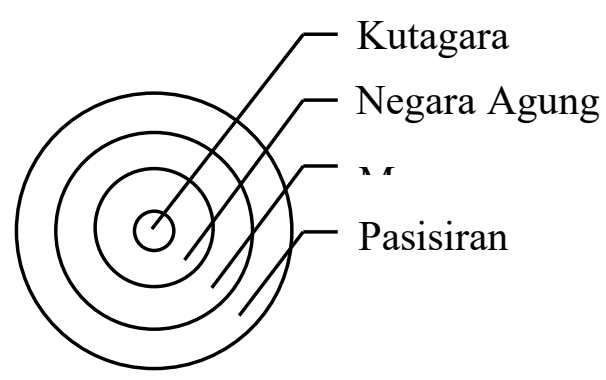

Gambar I. Lingkaran Konsentris Wilayah Kerajaan Mataram Islam

Berdasarkan lingkaran konsentris, pusat pemerintahan Kerajaan Mataram Islam berada di wilayah Kutagara. Di sekitar Kutagara, terdapat wilayah Negara Agung yang meliputi Bagelan, Kedu, Pajang dan Bumi Gede. Bagelan terletak di Jawa bagian tengah antara sungai Bagawanta dan Jali, Kedu terletak di sebelah utara Bagelan dan menjadi aliran sungai Praga bagian hulu, Pajang terletak di barat-daya kota Surakarta, dan Bumi Gede terletak di barat-daya kota Semarang antara Ungaran dan Kedungjati. Di luar Negara Agung terdapat Mancanegara Wetan meliputi Magetan, Madiun, Grobogan Kaduwung, Jogorogo, Ponorogo, Pacitan, Kediri, Jipang, Wirasaba, Blitar, Srengat, Lodaya, Pace, Nganjuk, Berbek, Cakuwu, dan Wirasari, dan Mancanegara Kulon meliputi Purwokerto, Banyumas, Sumedang, Bandung, dan lain sebagainya. Di luar wilayah Mancanegara terdapat Pasisiran Wetan (Demak ke timur: Jepara, Kudus, Pati, Rembang, Lasem, Tuban, Sedayu, Lamongan, Gresik, Surabaya, Pasuruan, dan Blambangan) dan Pasisiran Kulon (Demak ke barat: Semarang, Kendal, Pekalongan, Pemalang, Tegal, Brebes, Cirebon, Indramayu, dan Karawang) (Munawar, 2020).

Sebagai raja yang menguasai seluruh wilayah di atas, Sultan Agung melakukan kebijakan-kebijakan ekonomi-politik untuk mengelola tanah-tanah yang ada agar terkelola dengan baik. Pertama, kebijakan diawali dengan menunjuk para pejabat/wakilnya baik di wilayah Kutagara, Negara Agung, Mancanegara maupun Pasisiran untuk membantu mengurusi tanah kekuasaan di wilayah masing-masing. Di Kutagara, ditunjuk patih-lebet yang membawahi wedana-lebet, dan setiap wedana dibantu oleh 1 kliwon, 1 kebayan dan 40 mantri jajar. Di Negara Agung ditunjuk patihjawi yang membawahi wedana-jawi, dan setiap wedana dibantu oleh seorang bupati dan demang atau kyai lurah. Di Mancanegara ditunjuk para bupati dengan gelar Tumenggung atau Raden Arya dan di Pasisiran juga ditunjuk para bupati atau dikenal Syahbandar dengan gelar Tumenggung, Kyai Demang atau Raden Ngabehi (Moedjanto, 1987). Dengan begitu raja sebagai pusat aktivitas dapat mengetahui perkembangan yang ada di pelbagai wilayah kekuasaannya.

Kedua, Sultan Agung membagi tanah berdasarkan lingkaran konsentris wilayah Kerajaan Mataram Islam. Kebijakan ini dilakukan dengan tujuan untuk membangun masyarakat yang berada dalam naungan pemerintahannya. Di antara tanah yang dibagi yaitu: 
1. Tanah narawita. Tanah ini berada di Kutagara dan Negara Agung yang merupakan wilayah pusat dan inti kerajaan. Dalam mengelola tanah narawita raja menunjuk patuh untuk kemudian diserahkan kepada para petani untuk menggarapnya. Tanah-tanah tersebut dikelola menjadi lahan pertanian dengan padi sebagai tanaman utama. Selain pertanian, tanah narawita juga dikelola menjadi lahan perkebunan untuk menghasilkan rumput, bunga, minyak dan lain sebagainya. Hasil yang didapat dari tanah narawita diperuntukkan terutama bagi kebutuhan kerajaan (Hatmosuprobo, 1980).

2. Tanah perdikan. Tanah ini berada di daerah pedesaan terutama di wilayah Negara Agung yang diberikan kepada para tokoh agama seperti ulama dan penghulu. Tanah perdikan dimanfaatkan untuk membangun tempat ibadah, makam dan semacamnya yang dibebaskan dari pungutan pajak (Moertono, 1985).

3. Tanah lungguh/apanage. Tanah ini lebih luas dibandingkan dengan tanah narawita dan tanah perdikan sebab tersebar di wilayah Negara Agung, Mancanegara dan Pasisiran yang dibagikan kepada para bangsawan dan pejabat tinggi sebagai gaji atas kontribusi yang diberikan kepada kerajaan. Pengelolaan tanah lungguh dipercayakan kepada para bupati di wilayahnya masing-masing (Hatmosuprobo, 1980). Contoh tanah lungguh di Negara Agung, misalnya, Kedu, Bumi Gede dan Pajang. Masing-masing daerah tersebut dibagi menjadi dua: Kedu meliputi daerah Siti Bumi dan Bumija di sebelah barat dan timur Sungai Progo; Bumi Gede terletak di antara Pajang dan Demak yang mencakup daerah Sewu, terletak di antara Sungai Bogowonto dan Sungai Donan di Cilacap, dan daerah Numbak Anyar yang terletak di antara Sungai Bogowonto dan Sungai Progo; dan Pajang mencakup daerah Panumpang yang meliputi Sukowati dan daerah Panekar (Pusponegoro \& Notosusanto, 1984).

Ketiga, Sultan Agung menentukan luas tanah lungguh yang didapat oleh para bangsawan dan pejabat kerajaan berdasarkan tinggi rendahnya derajat kebangsawanan dan jabatan dalam struktur birokrasi kerajaan. Untuk bangsawan setingkat Ibu (Ratu Ibu) dan istri raja (Ratu Kencana) mendapat 1000 cacah (1 cacah $/$ karya $=4$ bahu) dan Adipati Anom 8000 cacah. Untuk pejabat setingkat patih mendapat 20.000 cacah. Untuk pejabat setingkat wedana-lebet mendapat 5000 cacah, sedang wedana-jawi luas tanah yang didapat tidaklah sama, tergantung dari luas tanah yang diperintahnya. Misalnya, wedana bumi dan wedana bumija, masingmasing mendapat 6000 cacah, sedang wedana siti ageng kiwa dan wedana siti ageng tengen, masing-masing 10.000 cacah. Hak memegang tanah oleh para pejabat tersebut sewaktu-waktu dapat dikurangi dan bahkan dicabut kembali oleh raja sebagai pemilik tanah karena suatu hal, misalnya pejabat yang bersangkutan melakukan kesalahan, tidak setia atau tidak patuh terhadap perintah raja (Moedjanto, 1987; Pusponegoro \& Notosusanto, 1984).

Keempat, Sultan Agung memprioritaskan pengelolaan tanah untuk sektor pertanian karena kondisinya yang subur dengan air yang melimpah. Pendistribusian tanah, terutama tanah lungguh, tidak lain adalah agar dapat dikelola secara maksimal untuk pertanian. Sebab pada masanya pertanian menjadi sumber utama bagi 
perekonomian kerajaan. Tanah pertanian ini dikelola melalui para patuh (bangsawan dan pejabat tinggi kerajaan) yang telah ditunjuk oleh Sultan Agung (Suratmin, 1982). Para patuh kemudian menugaskan para pejabat di bawahnya, mulai dari bupati, demang/lurah, hingga sampai kepada bekel. Melalui para bekel, tanah kemudian diserahkan kepada para petani untuk digarap. Jika tanah palungguh masih berupa hutan belukar, maka pemegang lungguh memerintahkan para petani untuk mengolah dan menjadikannya tanah usaha, terutama untuk pertanian (Hatmosuprobo, 1980).

Dalam konteks Kerajaan Mataram Islam, hubungan antara Sultan Agung sebagai raja dengan para petani terjalin dengan ikatan kawula-gusti, yaitu hubungan antara hamba dengan tuan yang saling melindungi kepentingan masing-masing. Hal ini terjadi karena adanya hubungan feodal yang mendasarkan atas pemilikan tanah. Hubungan terjadi setelah tanah diserahkan kepada petani dari patuh dan petani mengerjakan tanah tersebut dengan kewajiban menyerahkan sebagian hasil tanah dan tenaga kerja. Raja memiliki kekuasaan yang tidak dapat diubah atau dikurangi oleh siapa pun. Kekuasaan duniawi didasarkan atas hubungan feodal, sedangkan kekuasaan surgawi didasarkan adanya kultus dewa raja, artinya pemujaan raja sebagai titisan dewa yang ada di dunia petani harus setia kepada raja karena raja sama dengan dewa di dunia. Ketentraman batin petani juga sangat tergantung dari rajanya yang menjadi pelindung petani baik lahiriah maupun batiniah (Hatmosuprobo, 1980).

Upaya Sultan Agung untuk meningkatkan pertanian dilakukan dengan berbagai cara. Pertama, membuat danau atau lautan buatan di Plered sebagai bendungan untuk menampung air dengan memanfaatkan Sungai Opak yang mengalir di dekat kota. Van Goens melaporkan, air tersebut dialirkan ke lahan-lahan persawahan, tempat-tempat pemandian dan rumah-rumah penduduk melalui saluran air yang terbuat dari batu dan melalui sungai-sungai kecil lainnya (Adrisijanti, 2000; Lombard, 1996). Kedua, mengolah tanah pertanian untuk ditanami padi sebagai komoditi utama negeri Mataram. Pekerjaan ini dilakukan pada saat musim hujan ketika penduduk sedang tidak melakukan peperangan, yaitu antara Desember hingga Februari. Setelah memasuki bulan Maret hingga Mei, petani melakukan panen padi dan memasukkannya ke dalam lumbung-lumbung. Usai masa panen selesai, dimulailah ekspansi wilayah dan ekspedisi terhadap bupati-bupati yang berontak (Sabdacarakatama, 2010). Sebab pada masanya, hubungan antara pusat dan daerah, terutama Jawa bagian tengah, sering kali mengalami pasang surut dan berakibat terhadap banyaknya wilayah taklukkan yang bertindak secara merdeka sehingga penguasa pusat tiap kali pula perlu memerangi lagi agar dapat meletakkan hegemoninya (Kartodirdjo, 1992).

Ketiga, untuk meningkatkan produksi beras, maka Sultan Agung melakukan upaya intensifikasi tanaman padi. Adapun langkah yang dilakukan yaitu memperkuat kerja sama antara petani dan antar kelompok tani, baik dalam tertib pola tanam, penggunaan air irigasi, pengendalian hama dan penyakit, penggunaan peralatan maupun dalam panen (Guntoro, 2004). Upaya intensifikasi ini seringkali dibarengi dengan kebijakan pemindahan penduduk, baik keluar maupun masuk wilayah Mataram. Menurut Susilowati et al. (2010), fenomena perpindahan penduduk (migrasi) 
erat kaitanya dengan faktor penyebaran dan distribusi penduduk yang tidak merata serta tidak luput dari adanya faktor pendorong (push factor) dan penarik (pull factor). Namun secara umum, faktor paling dominan adalah faktor ekonomi. Perpindahan penduduk dalam konteks Kerajaan Mataram Islam disebabkan oleh faktor dorongan politik dan ekonomi, yaitu adanya perintah dari seorang raja kepada rakyatnya untuk mengelola tanah-tanah kekuasaan menjadi tanah pertanian guna mendukung program intensifikasi tanaman padi. Sebagai contoh, ketika Sultan Agung telah berhasil menaklukkan pelbagai wilayah di Jawa bagian timur, ia memindahkan penduduk taklukkan ke pusat Mataram untuk meningkatkan tenaga kerja dalam penanaman padi (de Graaf, 1989).

Pemindahan penduduk untuk mendukung program intensifikasi tanaman padi juga dilakukan Sultan Agung ke wilayah Mancanegara dan Pasisiran. Pada tahun 1632, Kerajaan Mataram Islam berhasil menaklukkan kekuatan-kekuatan wilayah Jawa bagian barat, seperti Sunda, Cirebon, Karawang, dan yang lainnya. Sultan Agung mengirim para petani ke Cirebon, Dermayu, dan sebenarnya juga semua dataran pantai di sebelah barat untuk kembali menghuni dan menyuburkan tanah-tanah pertanian (Sabdacarakatama, 2010; Tim Yayasan Mitra Budaya Indonesia, 1982). Di tahuntahun sebelumnya, untuk mendukung penyerangan Mataram ke Batavia yang diduduki VOC, Sultan Agung mengetatkan program intensifikasi tanaman padi di daerah Pantai Utara Jawa dengan tujuan untuk memenuhi kebutuhan pangan masyarakat setempat, di samping untuk kebutuhan pangan tentara yang jumlahnya sangat besar. Selama masa Sultan Agung, lokasi intensifikasi tanaman padi berpindah dari satu tempat ke tempat lain. Hal ini dilakukan karena menyesuaikan dengan rencana pengerahan pasukan dalam rangka ekspansi wilayah (Guntoro, 2004).

Dalam mendukung program intensifikasi, Sultan Agung menerapkan sistem pertanian terpadu, yaitu antara tanaman dan ternak. Menurut Kusnadi (2008) dan Hamdani (2008), sistem pertanian terpadu tanaman dan ternak merupakan sistem pertanian yang dicirikan oleh keterkaitan yang erat antara komponen tanaman dan ternak dalam suatu kegiatan usaha tani. Sistem pertanian ini sangat berpengaruh terhadap peningkatan pendapatan petani. Dalam konteks ini, Sultan Agung telah menerapkan sistem pertanian terpadu yang didukung dengan penerapan pola integrasi antara padi dan ternak, yaitu kerbau dalam mengelola persawahan. Tenaga kerbau digunakan untuk mengolah atau membajak tanah, sedangkan kotorannya diolah untuk dijadikan pupuk pertanian. Sebaliknya, limbah-limbah pertanian seperti damen (jerami padi) dan titen (jerami palawija) dimanfaatkan untuk pakan kerbau. Damen dan titen oleh masyarakat biasanya disimpan sebagai persediaan pangan kerbau ketika musim kemarau tiba, karena pakan lain seperti rumput sulit didapat (Guntoro, 2004).

Dalam rangka maksimalisasi peningkatan bidang pertanian, Sultan Agung membentuk wadah forum komunikasi untuk sarana pembinaan bagi para petani/prajurit. Berbagai hal yang dibahas didalamnya menyangkut kebijakankebijakan kerajaan terutama persoalan militer dan pertanian. Hal terkait pertanian, misalnya, bagaimana meningkatkan kerjasama dalam pengolahan lahan, ketertiban 
menanam dan penggunaan modal. Adapun bahasan terkait militer seperti bagaimana menyusun strategi pertahanan dan keamanan di dalam peperangan (Guntoro, 2004). Berbagai kebijakan Sultan Agung pada bidang pertanian yang diterapkan melalui peraturan-peraturan yang ketat dan didukung dengan loyalitas para petani telah menghasilkan surplus beras di Kerajaan Mataram Islam (Moedjanto, 1986).

Serangkaian kebijakan Sultan Agung terhadap pengelolaan tanah di wilayah kekuasaannya mampu memberikan dampak positif terhadap stabilitas ekonomi di Kerajaan Mataram Islam yang ditunjukkan dengan beberapa hal. Pertama, surplus beras di Kerajaan Mataram telah mendukung kesejahteraan istana, bangsawan, pejabat kerajaan hingga para petani. Hasil yang didapat dari pertanian berupa beras dibagi dengan persentase keraton/istana $24 \%$, bupati $8 \%$, demang/ngabehi $8 \%$, bekel $20 \%$ dan petani $40 \%$ (Hatmosuprobo, 1980). Melihat pembagian ini, meskipun hasil yang diterima oleh istana dan para pejabat kerajaan lebih kecil daripada petani, tetapi karena membawahi banyak tanah lungguh, maka hasil yang terkumpul menjadi lebih banyak. Terutama istana, karena pemasukan tidak hanya dari pajak bumi/tanah melainkan juga dari pajak penduduk, upeti dan bea cukai barang dan jasa, maka perbendaharaan kerajaan menjadi semakin kaya (Munawar, 2020).

Kedua, akibat surplus beras dan sistem monopoli perdagangan yang diterapkan, Kerajaan Mataram Islam mampu menancapkan pengaruhnya terhadap kekuatan atau wilayah lain melalui kegiatan ekspor-impor di pelabuhan Jepara. Dalam kegiatan ekspor, Mataram menjadi penyedia beras bagi Jambi, Palembang, Banjarmasin, VOC Belanda di Batavia, Portugis di Malaka, dan Kerajaan Gowa di Makassar (Kartodirdjo, 1992; Moedjanto, 1986; Reid, 1998). Dalam kegiatan impor, Mataram mendatangkan barang berupa sutera, porselin, rotan, permata, keramik merica, kayu, dan senjata meriam yang didapat dari para pedagang asing terutama Portugis melalui pelabuhan Jepara (Hartoyo, 1996; Moertono, 1985; Pranata, 1977).

Dalam sejarah ekspansi wilayah Kerajaan Mataram Islam, komoditi beras sangat membantu bidang kemiliteran. Beras menjadi logistik utama para prajurit saat melakukan peperangan. Persediaannya memberikan pengaruh terhadap tingkat keberhasilan di setiap penaklukkan wilayah. Kecuali ketika peperangan menghadapi VOC Belanda sebagai kekuatan besar di Batavia, salah satu yang menjadi penyebab kekalahan Kerajaan Mataram Islam adalah karena kurangnya suplai logistik beras yang diberikan kepada para prajurit di saat peperangan. Namun meskipun demikian, era Sultan Agung tercatat telah mampu menguasai sebagian besar wilayah Jawa (kecuali Batavia dan Banten) dan beberapa wilayah di luar pulau Jawa seperti Madura, Pelembang, Sukadana, Banjarmasin dan Makassar sehingga dicap sebagai masa kejayaan Kerajaan Mataram Islam.

\section{Simpulan}

Sultan Agung sebagai seorang raja memiliki otoritas penuh dalam mengelola seluruh tanah di wilayah kekuasaan Kerajaan Mataram Islam. Maksimalisasi pengelolaan tanah Sultan Agung dilakukan dengan menerapkan beberapa kebijakan, 
yaitu: menunjuk para pejabat pengelola tanah dari pusat sampai daerah meliputi Kutagara, Negara Agung, Mancanegara dan Pasisiran; membagi tanah berdasarkan lingkaran konsentris wilayah kekuasaan ke dalam tiga jenis, yaitu tanah narawita, tanah perdikan dan tanah lungguh; menentukan luas tanah lungguh kepada para bangsawan dan pejabat kerajaan; dan memprioritaskan pengelolaan tanah untuk peningkatan sektor pertanian. Upaya Sultan Agung dalam meningkatkan pertanian ditempuh melalui berbagai cara, yaitu: membuat danau buatan dan saluran air untuk memperlancar irigasi sawah; menanam padi sebagai komoditi utama pertanian; menerapkan intensifikasi tanaman padi dengan penguatan kerja sama para petani, pemindahan penduduk untuk meningkatkan tenaga kerja, dan penerapan sistem pertanian terpadu antara padi dan kerbau; dan membentuk forum komunikasi untuk pembinaan para petani. Kebijakan pengelolaan tanah Sultan Agung telah berhasil meningkatkan produktivitas hasil pertanian berupa padi sehingga memberikan dampak positif bagi stabilitas ekonomi di Kerajaan Mataram Islam, yang terlihat dari terciptanya kesejahteraan istana, bangsawan, pejabat kerajaan, hingga para petani dan keberhasilan kerajaan dalam menancapkan pengaruhnya terhadap wilayah lain melalui kegiatan perdagangan ekspor dan impor serta ekspansi wilayah.

\section{Daftar Pustaka}

Adrisijanti, I. (2000). Arkeologi Perkotaan Mataram Islam. Jendela.

Budi Wirianto, A. (2001). Gung Binatara: Kekuasaan dan Moralitas Jawa, Kasus Religiusitas Sultan Agung di Mataram. Jurnal Ilmiah Bestari, 32 (XIV), 4652.

Burdah, I. (2017). THE POLITICS OF MATARAM KINGDOM DURING THE REIGN OF SULTAN AGUNG. Journal of Indonesian Islam, 11(1), 267-306. de Graaf, H. . (1989). Puncak Kekuasaan Mataram; Politik Ekspansi Sultan Agung. PT Pustaka Grafitipers.

Febri, D. (2016). Tinjauan Historis Perjuangan Sultan Agung dalam Perluasan Kekuasaan Mataram Tahun 1613-1645. Jurnal Pendidikan Dan Penelitian Sejarah, 4 (2).

Guntoro, S. (2004). CLC (Crop Live Stok Sistem) di Zaman Kerajaan Mataram. Tabloid Sinar Tani.

Hamdani, M. (2008). Sistem Pertaninan Terpadu untuk peningkatan produktivitas lahan dan kesejahteraan petani. Makalah. Workshop Teknologi Unutuk Masyarakat. Gedung KORPRI Serang-Banten, 24.

Haq, I. (1996). Economic doctrines of Islam: A study in the doctrines and their implications for poverty, employment and economic growth. The International Institute of Islamic Thought, Herndon, USA.

Hartoyo. (1996). Kejayaan Prajurit Mataram pada Pemerintahan Sultan Agung 16131646 dalam Perspektif Sumber-sumber Babad. Laporan Penelitian JARAHNITRA.

Hatmosuprobo, S. (1980). Palungguh Pada Jaman Kerajaan Mataram.Pembinaan Pengajaran Sejarah IKIP Sanata Dharma.

Kartodirdjo, S. (1992). Pengantar Sejarah Indonesia Baru: 1500-1900: Dari 
Emporium Sampai Imperium. Gramedia Pustaka Utama.

Kartodirdjo, S. (1995). Negara dan nasionalisme Indonesia: integrasi, disintegrasi, dan suksesi. PT Grasindo.

Kusnadi, U. (2008). Inovasi teknologi peternakan dalam sistem integrasi tanaman-ternak untuk menunjang swasembada daging sapi. Pengembangan Inovasi Pertanian, 1(3), 189-205.

Laksono, A. D. (2018). Apa itu Sejarah: Pengertian, Ruang Lingkup, Metode dan Penelitian. Derwati Press.

Lombard, D. (1996). Nusa Jawa: Silang Budaya, Jilid II dan III. PT Gramedia Pustaka Utama.

Moedjanto, G. (1986). Sultan Agung, Keagungan dan Kebijaksanaannya. YIPK Panunggalan Lembaga Javanologi.

Moedjanto, G. (1987). Konsep Kekuasaan Jawa; Penerapannya Oleh Raja-raja Mataram. KANISIUS.

Moertono, S. (1985). Negara dan Usaha Bina Negara: Studi tentang Mataram II, Abad XVI Sampai XIX. Jakarta: Yayasan Obor Indonesia.

Munawar, Z. (2020). Pengelolaan Pajak di Kerajaan Mataram Islam Masa Sultan Agung 1613-1645 M. JUSPI (Jurnal Sejarah Peradaban Islam), 2( 1), 10-23.

Pranata, S. (1977). Sultan Agung Hanyakrakusuma. P.T Yudha Gama Corp.

Pusponegoro, M. J., \& Notosusanto, N. (1984). Sejarah Nasional Indonesia. Balai Pustaka.

Reid, A. (1998). Dari Ekspansi hingga Krisis II: Jaringan Perdagangan Global Asia Tenggara, terj. Yayasan Obor Indonesia.

Ricklefs, M. C. (2008). Sejarah Indonesia Modern 1200-2004. Penerbit Serambi.

Sabdacarakatama. (2010). Ensiklopedia raja-raja tanah Jawa: silsilah lengkap raja-raja tanah Jawa dari Prabu Brawijaya V sampai Sri Sultan Hamengku Buwono X. Narasi.

Santosa, R. B. (2008). Dari Kabanaran Menuju Yogyakarta; Sejarah Hari Jadi Kota Yogyakarta. Dinas Pariwisata, Seni dan Kebudayaan Kota Yogyakarta.

Suratmin, D. (1982). Sejarah Perlawanan Terhadap Imperialisme dan Kolonialisme di Daerah Istimewa Yogyakarta. Proyek Inventarisasi dan Dokumentasi Sejarah Nasional.

Susilo, A. dan Y. A. (2020). Sultan Agung Hanyakrakusuma dan Eksistensi Kesultanan Mataram. DIAKRONIKA, 20 (2), 117.

Susilowati, H. S., Hutabarat, B., Rachmat, M., Sugiarto, S., Zakaria, A. K., Supriyadi, H., Purwoto, A., \& Supadi, W. B. (2010). Indikator Pembangunan Pertanian dan Pedesaan: Karakteristik Sosial Ekonomi Petani Padi. Laporan Hasil Penelitian. Pusat Analisis Sosial Ekonomi Dan Kebijakan Pertanian Departemen Pertanian Bogor, 1-142.

Tim Yayasan Mitra Budaya Indonesia. (1982).

Wasino, M., \& Endah Sri, H. (2018). Metode Penelitian Sejarah: dari Riset hingga Penulisan. Magnum Pustaka Utama. 